\title{
Influence of genetic background, growth latitude and bagging treatment on phenolic compounds in fruits of commercial cultivars and wild types of apples (Malus sp.)
}

\author{
Yajing $\mathrm{Li}^{1} \cdot$ Hongxia Sun ${ }^{1} \cdot$ Jindong $\mathrm{Li}^{1} \cdot$ Shu Qin ${ }^{1} \cdot$ Zimian Niu$^{3} \cdot$ Xiongwu Qiao $^{1} \cdot$ Baoru Yang ${ }^{1,2}$ (I)
}

Received: 31 October 2020 / Revised: 2 January 2021 / Accepted: 9 January 2021 / Published online: 12 February 2021

(c) The Author(s) 2021

\begin{abstract}
Phenolic compounds in apples 17 cultivars (Malus domestica Borkh.) and 3 wild forms (Malus sp.) were analyzed to study the impact of genetic background, growth site, and fruit bagging. The impact of altitude was studied in nine cultivars by analyzing fruits collected from orchards at three altitudes. Procyanidin B2 (71-628 $\mu \mathrm{g} / \mathrm{g}$ fresh weight), ( -)-epicatechin (35-357 $\mu \mathrm{g} / \mathrm{g})$, and chlorogenic acid (28-563 $\mu \mathrm{g} / \mathrm{g})$ were always the three most abundant phenolic compounds in the apple samples studied, except for the cultivar 'Qinguan', which had a very low content of ( -)-epicatechin $(13 \mu \mathrm{g} / \mathrm{g})$ and procyanidin B2 $(8 \mu \mathrm{g} / \mathrm{g})$. The wild apples of M. prunifolia (Willd.) Borkh were 5-times richer in epicatechin $(278 \mu \mathrm{g} / \mathrm{g})$ and procyanidin B2 $(628 \mu \mathrm{g} / \mathrm{g})$ than the commercial cultivars of M. domestica Borkh ( 86 and 54, respectively). Among the commercial cultivars, 'Qinguan' had the highest level of chlorogenic acid but the lowest content of flavan-3-ols, whereas 'Liuyuehong' was characterized by the highest content of quercetin glycosides. Procyanidin B2, and (-)-epicatechin correlated negatively, while other phenolics positively, with altitude. The response of phenolic compounds to altitude variation depended on latitude variation and genetic backgrounds. Bagging treatment reduced the contents of most phenolic compounds, with the impact of cultivars and length of re-exposure before harvest. This is also the first report on phenolic compounds in several important new cultivars, adding new knowledge on the compositional characteristics of global apple resources.
\end{abstract}

Keywords Phenolic compounds $\cdot$ Altitude $\cdot$ Apple cultivars $\cdot$ Wild apple $\cdot$ Bagging treatment $\cdot$ Malus domestica Borkh.

\section{Introduction}

Apples are among the most widely consumed fruits in the world. Apples are rich in phenolic compounds, vitamins and other phytochemicals [1-3]. Consumption of apples may reduce the risk of chronic diseases such as cancers, diabetes, cardiovascular diseases, and respiratory system dysfunction, but most of the health effects of apples have been largely ascribed to phenolic compounds [2-4]. Phenolic compounds reported in apples belong to five major classes, namely

Baoru Yang

baoru.yang@utu.fi

1 Shanxi Center for Testing of Functional Agro-Products, Shanxi Agricultural University, Taiyuan 030000, China

2 Food Chemistry and Food Development, Department of Life Technologies, University of Turku, 20014 Turku, Finland

3 College of Horticulture, Shanxi Agricultural University, Taiyuan 030000, China flavan-3-ols (e.g. catechin, epicatechin and the oligomers procyanidins), phenolic acids (e.g. chlorogenic acid), flavonols (e.g. quercetin glycosides), dihydrochalcones (e.g. phloridzin), and anthocyanins (e.g. cyanidin-3-O-galactoside) [5]. Among them, procyanidin $\mathrm{B} 2$ and (-)-epicatechin have been reported to be beneficial to the cardiovascular and neuropsychological health and procyanidin B2 has also shown anticancer effects [6-8]. Chlorogenic acid modulates the metabolism of lipids and glucose in subjects with metabolic disorders and chronic diseases such as hepatic steatosis, cardiovascular disease, diabetes, and obesity [9]. The dihydrochalcone, phloridzin, has an effect on the secretion of gastrointestinal hormone and plays a role in the prevention of bone loss [10] and inhibition of senescence [11]. Flavonoid glycosides have potential in supporting cardiovascular health and has been used in the treatment of chronic venous insufficiency in some countries [12]. The phenolic composition of the apple cultivars and varieties directly affects their value as a dietary source of bioactive compounds and raw materials of functional foods. 
Additionally, phenolic compounds are also key components contributing to astringency and bitterness of apples, and play a role in color, aroma, and flavor of apple products such as apple cider and apple vinegar. For example, flavonols were reported to have very low thresholds for astringency [13]. Proanthocyanidins mainly taste bitter and astringent, and in water solution, the threshold of proanthocyanidin dimers for astringency and bitterness were 208 and $120 \mathrm{mg} / \mathrm{L}$, respectively [14]. The degree of polymerization (DP) plays a role in influencing the perceived bitterness of proanthocyanidins, oligomers being likely more bitter than proanthocyanidin polymers with high DP values [15]. Dihydrochalcones have been widely used as flavor enhancers and bitterness blockers in beverage, food, and pharmaceutical products [16]. Phloridzin and chlorogenic acid are two major phenolic compounds in apple fruit. Phloridzin is a commonly known bitter compound contributing to the bitterness of both apples and apple ciders, whereas chlorogenic acid, a non-bitter phenolic acid, is a precursor of a range of bitter compounds which can be formed as degradation products of chlorogenic acid during processing [17]. Thus, the composition and content of phenolic compounds may also have a key influence on the sensory quality of apples and apple products.

Phenolic compounds in apples have a very complex composition, which varies among different cultivars and is influenced by environmental factors such as light, temperature, relative humidity, precipitation, and soil conditions [1, 18]. Some studies reported that ancient apple varieties and wild apple species, which often do not have attractive appearance or flavor, contain higher levels of phenolic compounds and stronger antioxidative activities than the fruits of the commercially cultivated apple cultivars $[1,2]$. Lin-Wang et al. [19] reported that high growth temperature reduces the concentrations of anthocyanins in apple fruits. The study of Zhao et al. [18] indicated that high relative humidity increased the concentrations of phenolic compounds in apples. There have been some reports on the influence of single environment factor such as irradiation [20], temperature $[19,21]$, and relative humidity [18] on the selected phenolic compounds in apples. Bakhshi et al. [22] reported that the effect of UV-B irradiation on the accumulation of the phenolic compound in 'Jonathan' apple was influenced by bagging, temperature and maturation, indicating that the effect of a single factor often depends on the interaction with multiple factors. However, very little research has been directed to investigation on the effects of altitude and/or latitude of growth sites, which involves multiple environmental factors, on phenolic compounds in apples. Therefore, more systematic research in this field is needed.

Shanxi Province (China) located in the eastern part of the Loess Plateau has rich apple resources with about 200 cultivars/varieties/forms cultivated sporadically or as genetic resources, and the phenolic composition of these valuable resources has been rarely studied. In this study, we selected 17 cultivars including major conventional and newly developed ones as research targets. Three common forms of local wild apples were also studied as a comparison. Our aim was to systematically investigate the profiles and contents of phenolic compounds in these apple resources with special reference to the impact of genetic background and growth location, especially altitude, on phenolic compounds in apple fruits. The three major apple cultivation areas in Shanxi Province were selected, which differed considerably in altitude however with little variation in latitude and longitude. In addition, one apple cultivation area in Yunnan province with a high altitude was also included as a comparison. Fruit bagging is a common practice used in the production of apples to protect the fruit against damage from insects, birds, diseases, and mechanical scratches. Thus, in this study, we also investigated the effects of fruit bagging treatment on the content and composition of phenolic compounds in the fruits. The findings of this research form a new addition to the current knowledge on the composition of global apple production and provide guidance for apple breeding and cultivation as well as industrial utilization.

\section{Materials and methods}

\section{Chemicals}

Acetone, petroleum ether, acetonitrile, and formic acid of HPLC grade or the highest grades available, were purchased from Fisher Scientific Ltd (Nidderau, Germany). Reference compounds (+)-catechin (99.5\%), (-)-epicatechin (96.7\%), coumalic acid (99.5\%), syringic acid (98.5\%), phloretin (98.9\%), phloridzin (99.8\%), and quercetin-3-O-glucoside (99.6\%) were purchased from Anpel Laboratory Technologies Ltd (Shanghai, China). $P$-coumaric acid (99.3\%), caffeic acid (99.8\%), and quercetin-3-O-rhamnoside (98.7\%) were purchased from Aladdin Ltd (Shanghai, China). Ferulic acid (99.8\%), chlorogenic acid (99.3\%), neochlorogenic acid $(99.1 \%)$, gallic acid (99.8\%), cinnamic acid (99.4\%), sinapic acid (99.7\%), p-hydroxybenzoic acid (99.9\%), quercetin-3-O-galactoside (98.7\%), quercetin-3- $O$-arabinoside $(99.4 \%)$, quercetin-3- $O$-xylopyranoside $(98.5 \%)$, quercetin-3-O-rutinoside (98.0\%), and quercetin (98.7\%) were purchased from Yuanye Ltd (Shanghai, China). Procyanidin B2 (98.1\%) was purchased from Hongyong Ltd (Shanghai, China), and protocatechuic acid (99.9\%) was obtained from the National Institute of Food and Drug Control (NIFDC, Beijing, China). 


\section{Collection and pretreatment of samples}

Information of all the apple samples collected and analyzed is listed in Table 1. Altogether seventeen cultivars of M. domestica Borkh. $(n=160)$ and three forms of crabapples $(n=15)$, also known as wild apples (Malus sp.), were harvested during August-October 2018 in Shanxi, China. Three sampling location at different altitudes were selected in Shanxi, 5 biological replicates for each cultivar at each growth site. The fruits of all the cultivars received bagging treatment during their growth except those of the three wild forms and some early and medium early ripe cultivars (Table 1). For the cultivar 'Starkrimson', both bagged and unbagged samples were collected from two sites with different altitude, and for the cultivar 'Qinguan' from one site only. The bagged samples of 'Starkrimson' at 500-700 altitude were harvested on the fifth day after removal of the bags, and the rest samples were harvested on the tenth day after the bag removal. In addition, two cultivars 'Qinguan' $(n=5)$ and 'Xinshiji' $(n=5)$ were also collected in Yunnan Province from a higher altitude of around $2000 \mathrm{~m}$ as a comparison in the investigation of the effect of altitude on

Table 1 Information of apple samples collected and analyzed

\begin{tabular}{|c|c|c|c|c|c|c|}
\hline \multirow[t]{2}{*}{ Samples } & \multirow[t]{2}{*}{ Abbreviations } & \multicolumn{4}{|l|}{ Growth site } & \multirow[t]{2}{*}{ Fruit bagging } \\
\hline & & Altitude (m) & Latitude & Longitude & Name & \\
\hline \multicolumn{7}{|l|}{ Wild Apples (Malus genus) } \\
\hline M. prunifolia (Willd.) Borkh & - & $800-1000$ & $37^{\circ} 25^{\prime} \mathrm{N}$ & $112^{\circ} 32^{\prime} \mathrm{E}$ & Jinzhong, Shanxi & Without \\
\hline M. robusta Rehd & - & $800-1000$ & $37^{\circ} 25^{\prime} \mathrm{N}$ & $112^{\circ} 32^{\prime} \mathrm{E}$ & Jinzhong, Shanxi & Without \\
\hline M. domestica 'Saiwaihong' & - & $1000-1200$ & $36^{\circ} 07^{\prime} \mathrm{N}$ & $110^{\circ} 39^{\prime} \mathrm{E}$ & Linfen, Shanxi & Without \\
\hline \multicolumn{7}{|c|}{ Cultivated Apples (Malus domestica Borkh.) } \\
\hline \multirow[t]{2}{*}{ Gala } & GL & $500-700$ & $34^{\circ} 43^{\prime} \mathrm{N}$ & $110^{\circ} 41^{\prime} \mathrm{E}$ & Yuncheng, Shanxi & With \\
\hline & & $800-1000$ & $37^{\circ} 25^{\prime} \mathrm{N}$ & $112^{\circ} 32^{\prime} \mathrm{E}$ & Jinzhong, Shanxi & Without \\
\hline \multirow[t]{3}{*}{ Starkrimson } & STA & $500-700$ & $35^{\circ} 09^{\prime} \mathrm{N}$ & $110^{\circ} 47^{\prime} \mathrm{E}$ & Yuncheng, Shanxi & With and Without \\
\hline & & $800-1000$ & $37^{\circ} 41^{\prime} \mathrm{N}$ & $112^{\circ} 43^{\prime} \mathrm{E}$ & Jinzhong, Shanxi & With \\
\hline & & $1000-1200$ & $36^{\circ} 07^{\prime} \mathrm{N}$ & $110^{\circ} 39^{\prime} \mathrm{E}$ & Linfen, Shanxi & With and Without \\
\hline \multirow[t]{3}{*}{ Golden Delicious } & GOL-D & $500-700$ & $34^{\circ} 43^{\prime} \mathrm{N}$ & $110^{\circ} 41^{\prime} \mathrm{E}$ & Yuncheng, Shanxi & With \\
\hline & & $800-1000$ & $37^{\circ} 25^{\prime} \mathrm{N}$ & $112^{\circ} 32^{\prime} \mathrm{E}$ & Jinzhong, Shanxi & With \\
\hline & & $1000-1200$ & $36^{\circ} 42^{\prime} \mathrm{N}$ & $110^{\circ} 57^{\prime} \mathrm{E}$ & Linfen, Shanxi & With \\
\hline \multirow[t]{3}{*}{ Red General Fuji } & RGF & $500-700$ & $34^{\circ} 43^{\prime} \mathrm{N}$ & $110^{\circ} 41^{\prime} \mathrm{E}$ & Yuncheng, Shanxi & With \\
\hline & & $800-1000$ & $38^{\circ} 03^{\prime} \mathrm{N}$ & $112^{\circ} 39^{\prime} \mathrm{E}$ & Jinzhong, Shanxi & With \\
\hline & & $1000-1200$ & $36^{\circ} 07^{\prime} \mathrm{N}$ & $110^{\circ} 39^{\prime} \mathrm{E}$ & Linfen, Shanxi & With \\
\hline \multirow[t]{3}{*}{ Nagafu No. 2} & NF-2 & $500-700$ & $34^{\circ} 43^{\prime} \mathrm{N}$ & $110^{\circ} 41^{\prime} \mathrm{E}$ & Yuncheng, Shanxi & With \\
\hline & & $800-1000$ & $37^{\circ} 25^{\prime} \mathrm{N}$ & $112^{\circ} 32^{\prime} \mathrm{E}$ & Jinzhong, Shanxi & With \\
\hline & & $1000-1200$ & $36^{\circ} 07^{\prime} \mathrm{N}$ & $110^{\circ} 39^{\prime} \mathrm{E}$ & Linfen, Shanxi & With \\
\hline \multirow[t]{2}{*}{ Huimin Fuji } & $\mathrm{HF}$ & $500-700$ & $34^{\circ} 43^{\prime} \mathrm{N}$ & $110^{\circ} 41^{\prime} \mathrm{E}$ & Yuncheng, Shanxi & With \\
\hline & & $1000-1200$ & $36^{\circ} 07^{\prime} \mathrm{N}$ & $110^{\circ} 39^{\prime} \mathrm{E}$ & Linfen, Shanxi & With \\
\hline \multirow[t]{2}{*}{ Yantai Fuji No. 3} & YF-3 & $500-700$ & $35^{\circ} 25^{\prime} \mathrm{N}$ & $110^{\circ} 50^{\prime} \mathrm{E}$ & Yuncheng, Shanxi & With \\
\hline & & $1000-1200$ & $36^{\circ} 07^{\prime} \mathrm{N}$ & $110^{\circ} 39^{\prime} \mathrm{E}$ & Linfen, Shanxi & With \\
\hline \multirow[t]{3}{*}{ Qinguan } & QG & $500-700$ & $34^{\circ} 43^{\prime} \mathrm{N}$ & $110^{\circ} 41^{\prime} \mathrm{E}$ & Yuncheng, Shanxi & With \\
\hline & & $1000-1200$ & $36^{\circ} 07^{\prime} \mathrm{N}$ & $110^{\circ} 39^{\prime} \mathrm{E}$ & Linfen, Shanxi & With and Without \\
\hline & & Around 2000 & $25^{\circ} 08^{\prime} \mathrm{N}$ & $102^{\circ} 11^{\prime} \mathrm{E}$ & Yunnan & With \\
\hline \multirow[t]{2}{*}{ Xinshiji } & XSJ & $500-700$ & $35^{\circ} 09^{\prime} \mathrm{N}$ & $110^{\circ} 47^{\prime} \mathrm{E}$ & Yuncheng, Shanxi & With \\
\hline & & Around 2000 & $25^{\circ} 08^{\prime} \mathrm{N}$ & $102^{\circ} 11^{\prime} \mathrm{E}$ & Yunnan & With \\
\hline Yantai Fuji No. 6 & YF-6 & $500-700$ & $35^{\circ} 25^{\prime} \mathrm{N}$ & $110^{\circ} 50^{\prime} \mathrm{E}$ & Yuncheng, Shanxi & With \\
\hline Xiali & $\mathrm{XL}$ & $800-1000$ & $37^{\circ} 25^{\prime} \mathrm{N}$ & $112^{\circ} 32^{\prime} \mathrm{E}$ & Jinzhong, Shanxi & Without \\
\hline American No. 8 & USA-8 & $800-1000$ & $37^{\circ} 25^{\prime} \mathrm{N}$ & $112^{\circ} 32^{\prime} \mathrm{E}$ & Jinzhong, Shanxi & Without \\
\hline Starking Delicious & STA-D & $800-1000$ & $37^{\circ} 25^{\prime} \mathrm{N}$ & $112^{\circ} 32^{\prime} \mathrm{E}$ & Jinzhong, Shanxi & Without \\
\hline Lihong & LH & $800-1000$ & $37^{\circ} 25^{\prime} \mathrm{N}$ & $112^{\circ} 32^{\prime} \mathrm{E}$ & Jinzhong, Shanxi & Without \\
\hline Liuyuehong & LYH & $800-1000$ & $37^{\circ} 25^{\prime} \mathrm{N}$ & $112^{\circ} 32^{\prime} \mathrm{E}$ & Jinzhong, Shanxi & Without \\
\hline Qiufu No. 1 & QF-1 & $1000-1200$ & $36^{\circ} 07^{\prime} \mathrm{N}$ & $110^{\circ} 39^{\prime} \mathrm{E}$ & Linfen, Shanxi & With \\
\hline Zhongqiuwang & ZQW & $1000-1200$ & $36^{\circ} 07^{\prime} \mathrm{N}$ & $110^{\circ} 39^{\prime} \mathrm{E}$ & Linfen, Shanxi & With \\
\hline
\end{tabular}


phenolic compounds. The fruits were picked as optimally ripe as determined by an experienced apple cultivation expert based on surface color and size. For each cultivar, five samples were collected randomly from each site and analyzed separately as biological replicates. Each replicate consisted of six to eight apples. The apples were immediately stored at $0{ }^{\circ} \mathrm{C}$ after picking and transporting to the laboratory.

Before the extraction of phenolic compounds, the apples were decored and divided into 12 pieces using an apple slicer. And the apple pieces were immediately frozen by addition of dry ice and grounded into powders in a Knife Mill Grindomix GM 300 (Retsch Corp., Haan, Germany). After grinding, the frozen powders were stirred to evaporate the dry ice before transferring to storage at $-30^{\circ} \mathrm{C}$.

\section{Extraction of phenolic compounds}

About $5 \mathrm{~g}$ of frozen apple powder was weighted accurately and extracted with $25 \mathrm{~mL}$ of extracting solvent consisting of acetone, water and acetic acid (80/19.5/0.5, v/v/v) by sonicating for $5 \mathrm{~min}$ and thereafter vortexing for $5 \mathrm{~min}$. After the extraction, the mixture was centrifuged at $11,764 \mathrm{~g}$ for 15 min to separate the supernatant from the solid residue. The extraction was repeated once with $20 \mathrm{~mL}$ of extracting solvent. The supernatants from the two extractions were combined, and the total volume was adjusted to $50 \mathrm{~mL}$ with acetone in a volumetric flask. Thereafter an aliquot of $10 \mathrm{~mL}$ of the extract was accurately transferred into a $150 \mathrm{~mL}$ evaporation flask, and acetone was removed by a rotary evaporator under reduced pressure at $32{ }^{\circ} \mathrm{C}$. The sample was diluted with MilliQ water to a final volume of $5 \mathrm{~mL}$, and defatted by extracting with $2 \times 5 \mathrm{~mL}$ petroleum ether. Finally, the defatted extract was filtered through a $0.22 \mu \mathrm{m}$ polytetrafluoroethylene (PTFE) filter.

\section{Analysis of phenolic compounds using UPLC-PDA}

Chromatographic analyses were performed on a Waters Acquity Ultra Performance LC system (Waters Corp., Milford, MA) equipped with a PDA detector. The temperature of the column oven and the autosampler was maintained at $30{ }^{\circ} \mathrm{C}$ and $8{ }^{\circ} \mathrm{C}$, respectively. A Waters HSS T3 C-18 column $(2.1 \mathrm{~mm} \times 100 \mathrm{~mm}, 1.8 \mu \mathrm{m})$ was used for separating the phenolic compounds. The mobile phases consisted of two solvents: $0.1 \%$ aqueous solution of formic acid (A) and acetonitrile containing $0.1 \%$ formic acid (B). The linear gradient was as follows: $3 \% \mathrm{~B}$ from 0 to $2.5 \mathrm{~min}, 3-14.6 \% \mathrm{~B}$ from 2.5 to $6.75 \mathrm{~min}, 14.6-18 \% \mathrm{~B}$ from 6.75 to $10.25 \mathrm{~min}, 18 \% \mathrm{~B}$ from 10.25 to $14 \mathrm{~min}, 18-20 \%$ B from 14 to $15 \mathrm{~min}, 20-60 \%$ B from 15 to $19 \mathrm{~min}, 60-80 \% \mathrm{~B}$ from 19 to $21.25 \mathrm{~min}, 80 \% \mathrm{~B}$ from 21.25 to $26.25 \mathrm{~min}, 80-3 \%$ B from 26.25 to $32 \mathrm{~min}$, and $3 \% \mathrm{~B}$ from 32 to $38 \mathrm{~min}$. The flow rate of the mobile phase was $0.36 \mathrm{~mL} / \mathrm{min}$. UV-Vis spectra were scanned from 200 to $600 \mathrm{~nm}$, and chromatograms were recorded at three wavelengths, 280, 320, and $360 \mathrm{~nm}$, to detect flavanols, phenolic acids, and flavonols, respectively.

The compounds were quantified using external standard methods using calibration curves constructed with reference compounds.

\section{UPLC-ESI-MS analysis for identification of phenolic compounds}

The identification of the phenolic compounds in the extracts was further confirmed using high-performance liquid chromatography-electrospray ionization mass spectrometry performed with a Waters Acquity Ultra Performance LC system in combination with a Waters Quattro Premier mass spectrometer (Waters Corp., Milford, MA) equipped with an electrospray interface. The UPLC column and LC conditions were the same as described for the UPLC-PDA analysis in the previous section. The mass spectrometer was operated in both positive and negative ion modes. The capillary voltage was set at 3.5 and $3.6 \mathrm{kV}$, the cone voltage at 15 and $22 \mathrm{~V}$, and the extractor voltage at 3 and $4 \mathrm{~V}$ for positive and negative ion modes, respectively. The source temperature was set at $120^{\circ} \mathrm{C}$, desolvation temperature at $300{ }^{\circ} \mathrm{C}$, and the scan range was from $\mathrm{m} / \mathrm{z}, 100$ to $m / z, 1000$.

\section{Statistical analysis}

Statistical analyses were carried out with SPSS 24.0 (SPSS, Inc., Chicago, IL) and Unscrambler X10.4 (Camo Process AS, Oslo, Norway). The results were presented as means \pm SD (standard deviations). One-way analysis of variance (ANOVA) was performed for multiple comparisons, followed by Student-Newman-Keuls (SNK) test for a population with equal variances and Tamhane's T2 for a population with unequal variances, Independent-samples $t$-test was used to investigate the difference between the samples of the same cultivar collected at two altitudes. Bivariate correlation analysis and partial correlation analysis were performed to study the effects of altitudes of the growth places on the contents of phenolic compounds and the correlation between these compounds. A probability value of $p<0.05$ was considered statistically significant. In addition, principal component analysis (PCA) was applied to further investigate variations in the compositional profiles of the apple samples. 


\section{Results and discussion}

\section{Profiles of phenolic compounds in cultivars and wild forms of apples}

A total of 24 phenolic compounds were screened based on the previous reports of these compounds in apples, of which 15 compounds were detected and identified in the samples (Supplementary material S1) using UPLC-PDA (photo-diode array) and UPLC-MS (Supplementary material S1). The identification was based on the retention times, UV- and mass spectra, and reference compounds (Supplementary material S1 and S2). Ten compounds were quantified as major compounds present in all the samples, and the contents of these compounds in the samples are summarized in Table 2. The most abundant phenolic compounds in the samples studied fell into four groups: flavanols (mainly (-)-epicatechin and procyanidin B2), hydroxycinnamic acid derivatives (chlorogenic acid), flavonol glycosides (quercetin glycosides), and dihydrochalcones (phloridzin). Protocatechuic acid, $(+)$-catechin, free phloretin and quercetin aglycones were present in only trace amounts in apples and were not quantified. These findings were consistent with the reports of previous studies on phenolics in apple cultivars [23, 24].

It was reported that the monomeric forms of flavan3-ols, namely (+)-catechin and (-)-epicatechin, and the oligomeric proanthocyanidins are the main phenolic compounds in apples, which represent $55-85 \%$ of the total phenolic compounds [25]. In our present study, $(+)$-catechin, (-)-epicatechin and procyanidin B2 were detected in all the samples, but only ( - )-epicatechin and procyanidin B2 were present at levels sufficient for quantification. Procyanidin B2 (71-628 $\mu \mathrm{g} / \mathrm{g}$ fresh weight), ( -)-epicatechin $(35-357 \mu \mathrm{g} / \mathrm{g})$, and chlorogenic acid $(28-563 \mu \mathrm{g} / \mathrm{g})$ were always the three most abundant phenolic compounds in the apple samples studied, except for the cultivar 'Qinguan', which had a very low content of ( -$)$-epicatechin $(13 \mu \mathrm{g} / \mathrm{g})$ and procyanidin B2 $(8 \mu \mathrm{g} / \mathrm{g})$ (Table 2$)$. Twelve phenolic acids previously reported in apples were screened, but only chlorogenic acid (3-O-caffeoylquinic acid), neochlorogenic acid (5- $O$-caffeoylquinic acid), and some trace mount of protocatechuic acid were detected in most of the samples. Chlorogenic acid was quantified in all the samples with varying levels in the range of $28-563 \mu \mathrm{g} / \mathrm{g} \mathrm{FW}$. Neochlorogenic acid was quantified only in $M$. prunifolia (Willd.) Borkh $(5.47 \pm 0.15 \mu \mathrm{g} / \mathrm{g} \mathrm{FW})$, a wild apple variety. A study of free and bound phenolic acids in the peel and pulp of apples also indicated that only chlorogenic acid was present in free form, and all other the phenolic acids only existed in bound forms [26]. Similar results were obtained in the study conducted by Zupan [27]. With the method used in our study, only phenolic acids present in free form were extracted, therefore, only chlorogenic acid was quantified.

Dihydrochalcones and flavonols eluted generally in the latter part of the chromatograms. Phloridzin and six quercetin glycosides were quantified. For most of the samples studied, the content of phloridzin fell within the range of $10-30 \mu \mathrm{g} / \mathrm{g}$, the cultivar 'Gala' $(6 \mu \mathrm{g} / \mathrm{g})$ and the wild apple species $M$. robusta Rehd. ( $83 \mu \mathrm{g} / \mathrm{g})$ being with the exception with a very low and high level of this compound, respectively. Quercetin-3-O-galactoside (8-92 $\mu \mathrm{g} / \mathrm{g}$ ) was the most abundant quercetin glycoside in all the cultivars and wild forms studied, while quercetin-3-O-rutinoside $(0.3-3 \mu \mathrm{g} / \mathrm{g})$ was always the least abundant. The other glycosides were glucoside, xyloside, arabinoside, and rhamnoside of quercetin. The level of each of these compounds was typically $1-10 \mu \mathrm{g} / \mathrm{g} \mathrm{FW}$ in the commercial cultivars, whereas the content in the wild apples varied from 7 to $36 \mu \mathrm{g} / \mathrm{g} \mathrm{FW}$.

\section{Comparison between commercial cultivars and crabapples (wild apples)}

As shown in Table 2, the present study revealed clear differences in the content and composition of phenolic compounds between the commercially cultivated apples and the crabapples. For most of the phenolic compounds, the contents were significantly lower in the commercial cultivars than the corresponding levels in the crabapples, except chlorogenic acid, of which the average content in the commercial cultivars $(113.2 \mu \mathrm{g} / \mathrm{g})$ was higher than in crabapple $M$. prunifolia (Willd.) Borkh $(87.2 \mu \mathrm{g} / \mathrm{g})$. The results were consistent with some previous studies, which reported higher content of phenolic compounds in wild apple forms than in the commercial cultivars $[2,28,29]$. It must be pointed out that, in this study, most of the cultivated samples received bagging treatment, whereas the wild apples did not. This may have also contributed to the difference between the cultivated and the wild apples; however, the effect of bagging is likely less significant than that induced by the difference in genetic background between different species.

The wild apples are described as having bitter and astringent tastes as well as small size, while the cultivated apples have more juicy structure and more pleasant flavor as well as larger fruit size, as results of selection and breeding [29]. Flavonoids in apple fruits, including flavan-3-ols, flavonols, and anthocyanins, are frequently associated with a bitter taste when their contents exceed certain thresholds. High content of phenolic compounds is important contributors to the strong bitter taste and astringencies perceived of wild apples. In contrast, the lower levels of phenolic compounds in the cultivated apples are likely associated with a more pleasant taste, which is often the goal of domestication 


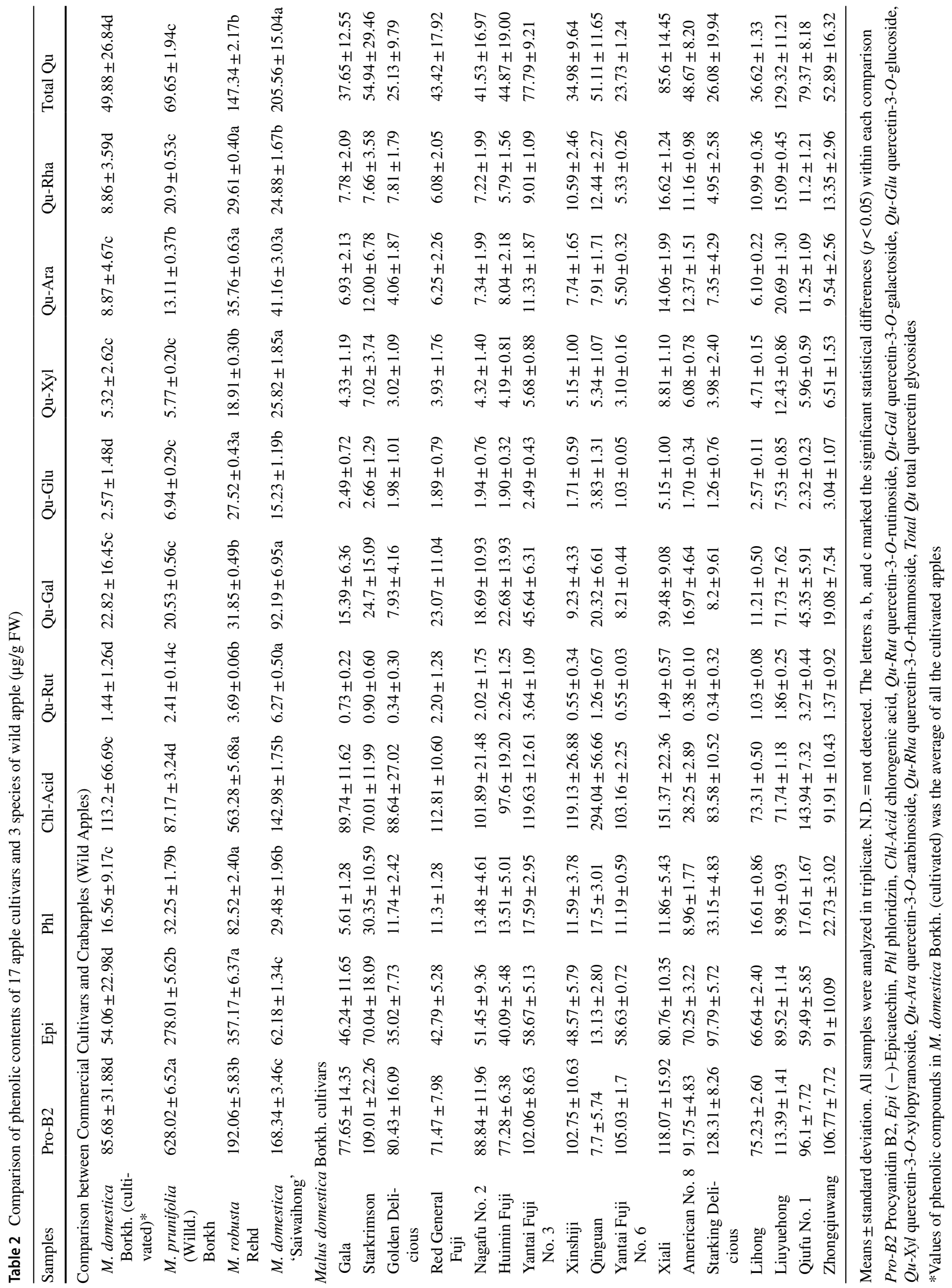


involving selection and breeding as well as various cultivation practices [29].

Clear differences were also found among the three wild forms in the composition of phenolic compounds. M. prunifolia (Willd.) Borkh had the highest content of procyanidin B2 $(628 \mu \mathrm{g} / \mathrm{g} \mathrm{FW})$, which was over threefold of the corresponding levels found in the other two forms (192 and $168 \mu \mathrm{g} / \mathrm{g}$, respectively). In addition, M. prunifolia (Willd.) Borkh was the only crabapple sample containing neochlorogenic acid at a quantifiable level $(5.47 \pm 0.15 \mu \mathrm{g} / \mathrm{g} \mathrm{FW})$. The samples of $M$. Robusta Rehd had the highest contents of ( -)-epicatechin $(357 \mu \mathrm{g} / \mathrm{g})$, phlorizin $(83 \mu \mathrm{g} / \mathrm{g})$ and chlorogenic acid $(563 \mu \mathrm{g} / \mathrm{g})$, the levels of the latter two compounds being threefold to sevenfold higher than those in others. In addition, the total content of quercetin glycosides as well as the content of most of the individual quercetin glycosides was the highest in M. domestica 'Saiwaihong'.

The difference between the commercially cultivated apples $(n=160)$ and the crabapples $(n=15)$ in the overall profile of phenolic compounds was further demonstrated by a PCA model (Fig. 1). The first two validated principal components (PC1 and PC2) together explained $78 \%$ of the total variance and separated the three wild forms from each other as well as from the cultivated samples. With high content of phenolic compounds, all the wild apples were located on the positive side of PC1, whereas the majority of the commercial cultivars were on the opposite side of PC1, characterized by a lower content of phenolic compounds. PC2 separates the samples based on the abundance of different groups of phenolic compounds. M. prunifolia is located close to procyanidin B2, and $M$. robusta close to phloritzin and (-)-epicatechin. M. domestica 'Saiwaihong' is located on the opposite side of PC2 due to the lower content of procyanidin B2 and (-)-epicatechin as well as the higher contents of quercetin glycosides.

\section{Comparison among commercial apple cultivars of $\boldsymbol{M}$. domestica Borkh.}

The contents of phenolic components in 17 cultivars/varieties of M. domestica Borkh. were summarized in Table 2. In general, the most abundant phenolic compounds in the apple samples analyzed were chlorogenic acid (28-294 $\mu \mathrm{g} / \mathrm{g} \mathrm{FW})$ and procyanidin B2 (8-128 $\mu \mathrm{g} / \mathrm{g} \mathrm{FW})$, followed by epicatechin $(13-98 \mu \mathrm{g} / \mathrm{g})$, and phlorizin $(6-33 \mu \mathrm{g} / \mathrm{g})$. The total content of quercetin glycosides was in the range of $24-129 \mu \mathrm{g} / \mathrm{g}$. Some cultivars such as 'Starkrimson', 'Starking Delicious', 'Liuyuehong', and 'Xiali' had high levels of procyanidin B2 and (-)-epicatechin, and their chlorogenic acid content was relatively low compared with the former two compounds. The content of procyanidin B2 was always higher than the content of (-)-epicatechin in most of the cultivars, except for 'Qinguan', where the situation was vice versa. Among
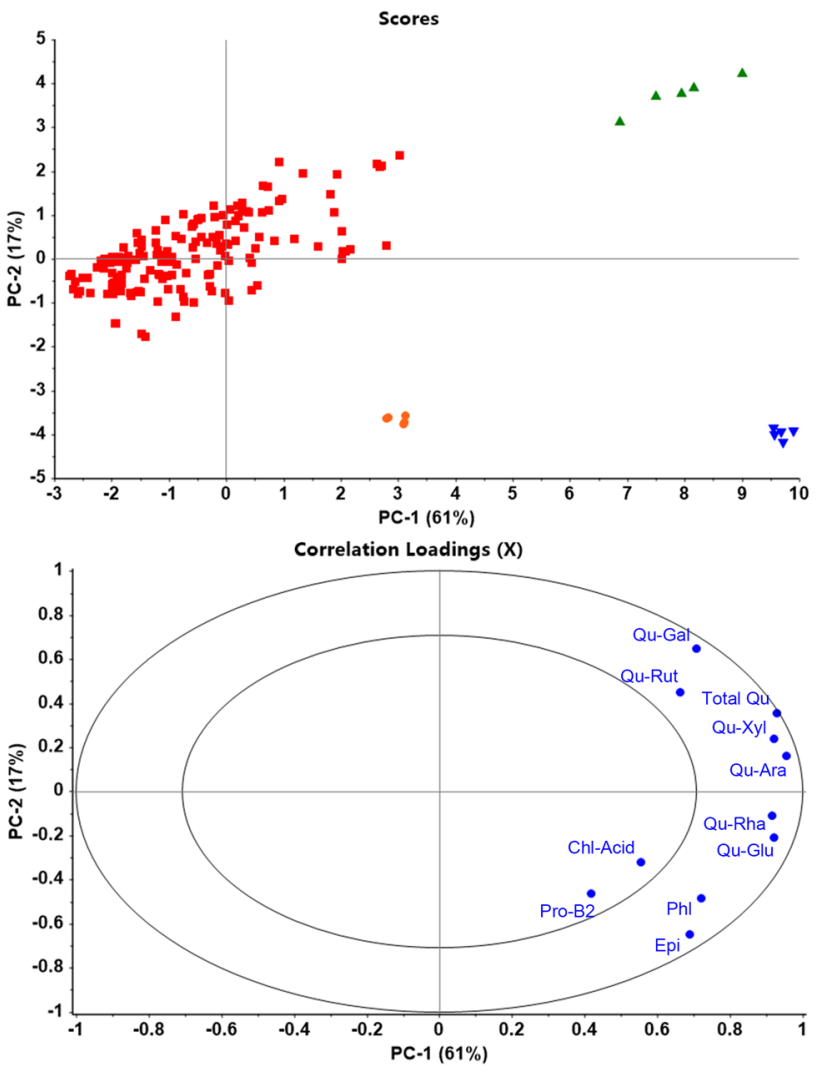

Fig. 1 Scores and loadings plots of PCA model with the first and second factors for all samples (Malus genus) analyzed classified according to the contents of phenolic compounds. ( $M$. domestica Borkh. (cultivated); M. prunifolia (Willd.) Borkh.; $\boldsymbol{\Delta}$ M. domestica 'Saiwaihong'; $\nabla_{M}$. Robusta Rehd.). Abbreviations of the compounds refer to Table 2

all cultivars, 'Starking Delicious' had the highest levels of procyanidin B2 $(128 \mu \mathrm{g} / \mathrm{g})$ and (-)-epicatechin $(98 \mu \mathrm{g} / \mathrm{g})$, whereas 'Qinguan' had the lowest content of these compounds ( $8 \mu \mathrm{g} / \mathrm{g}$ and $13 \mu \mathrm{g} / \mathrm{g}$, respectively) being about onetenth of the levels found in other cultivars. Chlorogenic acid $(294 \mu \mathrm{g} / \mathrm{g})$ was by far the most abundant phenolic compound in 'Qinguan', the content of being the highest among all cultivars. For the cultivar 'American No. 8' the situation was just the opposite, chlorogenic acid content being much lower $(28 \mu \mathrm{g} / \mathrm{g})$ than all other the cultivars $(70-294 \mu \mathrm{g} / \mathrm{g})$. In terms of phloridzin, the highest content was in 'Starkrimson' $(30 \mu \mathrm{g} / \mathrm{g})$ and 'Starking Delicious' ( $33 \mu \mathrm{g} / \mathrm{g})$, and the lowest content was in 'Gala' $(6 \mu \mathrm{g} / \mathrm{g})$.

Overall the seventeen cultivars showed quite similar profiles of quercetin glycosides. Among the glycosides of quercetin detected, quercetin-3-O-galactoside $(8-72 \mu \mathrm{g} / \mathrm{g})$ represented the most dominating compound in all analyzed cultivars, followed by quercetin-3-O-arabinoside (4-21 $\mu \mathrm{g} / \mathrm{g})$, quercetin-3-O-rhamnoside $(5-17 \mu \mathrm{g} / \mathrm{g})$, and quercetin-3- $O$-xyloside (3-12 $\mu \mathrm{g} / \mathrm{g})$. Quercetin-3-O-glucoside $(1-8 \mu \mathrm{g} / \mathrm{g})$ and quercetin-3-O-rutinoside $(0.3-4 \mu \mathrm{g} / \mathrm{g})$ 
were the less abundant components in this group. The total content of quercetin glycosides was the highest in 'Liuyuehong' $(129 \mu \mathrm{g} / \mathrm{g})$, followed by 'Xiali' ( $86 \mu \mathrm{g} / \mathrm{g})$, 'Qiufu No. 1' $(79 \mu \mathrm{g} / \mathrm{g})$, and 'Yantai Fuji No. 3' (78 $\mu \mathrm{g} / \mathrm{g})$. The lowest levels of flavonol glycosides were found in 'Golden Delicious' ( $25 \mu \mathrm{g} / \mathrm{g})$, 'Starking Delicious' $(26 \mu \mathrm{g} / \mathrm{g})$ and 'Yantai Fuji No. 6' (24 $\mu \mathrm{g} / \mathrm{g})$.

It is worth noticing that, most of the cultivars in our study received bagging treatment except the early ripening cultivars and some medium ripening cultivars grown in Jinzhong region, such as 'Gala', 'Xiali', 'American No. 8', 'Lihong', 'Starking Delicious', and 'Liuyuehong'. The bagging treatment likely had an impact on the difference detected in the contents of phenolic compounds among the cultivars/varieties. Detailed discussion on this aspect will be presented in later part of in this paper.

A PCA model (Fig. 2) was constructed for further exploration of the compositional differences among the 17 commercial cultivars (160 samples altogether). The model discriminated the cultivars with seven principle components (PCs), and the first two components (PC1 and PC2) contained $73 \%$ of the variance in the content of phenolic compounds. In the loading plot, all the glycosides of quercetin were all located on the right side of the first component. In addition, (-)-epicatechin and procyanidin B2 were located on the negative side of the second component, whereas
Fig. 2 Scores and loadings plots of PCA model with the first and second factors for cultivated apple samples classified according to contents of phenolic compounds. Fuji' apple in the scores plot including 'RGF', 'NF-2', 'HF', 'YF-3', 'YF-6' and 'QF1 ' apples. Abbreviations of the cultivars refer to Table 1 and abbreviations of the compounds refer to Table 2
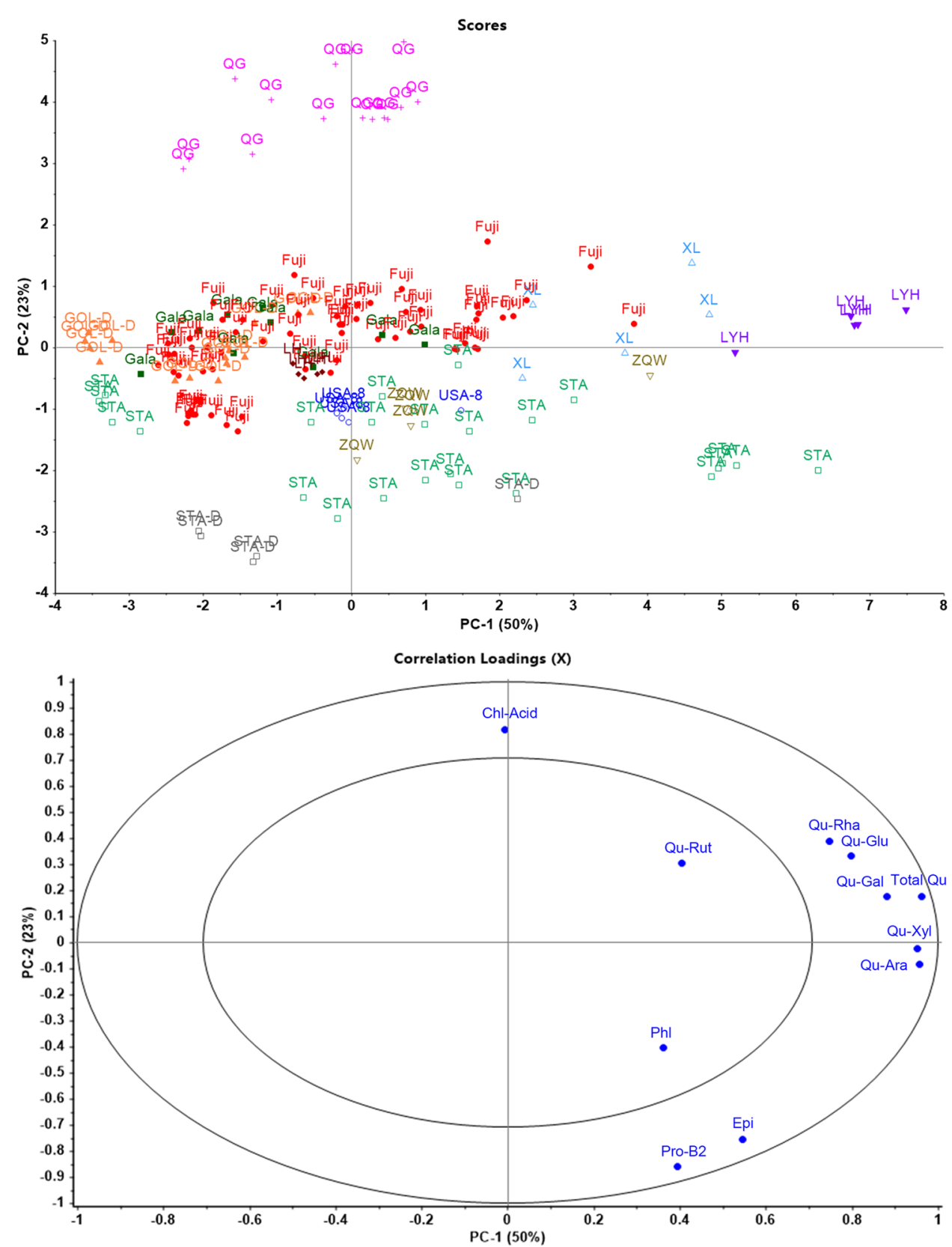
chlorogenic acid was on the opposite (positive) side of the second component. In the score plot, 'Liuyuehong' and 'Xiali', two early ripening cultivars were located on the right with strong positive correlation with most of the quercetin glycosides, whereas 'Golden Delicious' and 'Starking Delicious' located on the opposite side were characterized by lower levels of quercetin glycosides. 'Qinguan' was located on the positive side of the second component in the score plot, characterized by higher levels of chlorogenic acid and lower levels of (-)-epicatechin and procyanidin B2 compared to those of other cultivars. The cultivars 'Starkrimson' and 'Starking Delicious' located on the negative side of the plot are characterized by higher levels of these compounds. Other cultivars situated around the center of the score plot, indicating that there were no clear characteristics in the phenolic contents and profiles in these cultivars.

Previously published studies on the phenolic composition of apples have mostly focused on four cultivar series 'Golden Delicious', 'Fuji', 'Gala' and 'Red Delicious'. And there was no research published on content and composition of individual phenolic compounds in the fruits (decored edible parts) of the majority of the cultivars investigated in this study, although some reports focused on the contents of phenolic compounds in the juice of apples of 'Qin Guan' and 'Xinshiji' [30, 31]. In Supplementary material S3, we compiled the phenolic contents of selected cultivars belong to above four series included in this study in comparison with some published data on related cultivars reported in the literature [23, 24, 32-38]. Considerable variations in phenolic content and profile of apple cultivars were observed when comparing the results of the present study with the data reported of some related cultivars grown in other countries. The largest variation was found in the content of procyanidin B2. Overall, the content of procyanidin B2 in the cultivars of this study was similar as the levels reported in the same series cultivated in Zürich (Switzerland) [36], being much higher than the levels in the related cultivars grown in Portugal $[34,35]$. Genetic background, environmental factors as well as cultivation methods and horticultural practice in various regions might all have contributed to differences observed in the content and profile of phenolics.

It is important to point out that most of the previous studies did not clearly differentiate or define the variations within the series 'Fuji'. In the present study, we specifically studied five variations within 'Fuji' series including 'Nagafu', 'Yantai Fuji', 'QiuFu', 'Huimin Fuji', and the 'Red General Fuji'. Differences were recognized among the cultivars within the 'Fuji' series. 'Yantai Fuji' No. 3 and No. 6 and Qiufu No. 1 had clearly higher levels of procyanindin B2 (102, 106 and $96 \mu \mathrm{g} / \mathrm{g}$, respectively) and (-)-epicatechin $(59 \mu \mathrm{g} / \mathrm{g})$ than 'Red General Fuji' (71 and $43 \mu \mathrm{g} / \mathrm{g}$, respectively) and 'Huimin Fuji' (77 and $40 \mu \mathrm{g} / \mathrm{g}$, respectively). Qiufu No.1 had a much higher level of chlorogenic acid $(144 \mu \mathrm{g} / \mathrm{g})$ than other Fuji variations $(98-120 \mu \mathrm{g} / \mathrm{g})$. In the present study, the local main variations of 'Gala' were 'Royal Gala', 'Yan Gala', and 'Red Gala'. We were not able to define the exact variations of 'Gala' apples investigated in our study since different variations of 'Gala' apples were often mix-planted in the same orchards. Different variations within each cultivar series may have been investigated in different studies, which likely have also contributed to the differences in the results reported in various studies.

\section{Effect of altitudes on phenolic compounds}

The influence of altitude on the content of phenolic compounds was studied in nine main apple cultivars, and the information of individual cultivars collected from different altitudes are summarized in Table 1. In this study, cultivation sites of three altitude levels were selected in Shanxi Province, namely high altitude (1000-1200 m), medium altitude (800-1000 m), and low altitude (500-800 m). The latitudes of the growth sites ranged between $35^{\circ} 15^{\prime} \mathrm{N}$ and $37^{\circ} 87^{\prime} \mathrm{N}$. Moreover, two cultivars 'Qinguan' and 'Xinshiji' were also sampled from a very high altitude around $2000 \mathrm{~m}$ in Yunnan province (latitude, $21^{\circ} 8^{\prime} \mathrm{N}$ ) to further explore the effect of altitude on the phenolic composition of these apple cultivars.

As shown in Table 3, the levels of procyanidin B2 and (-)-epicatechin were always the highest in the apple samples collected from medium altitude $(800-1000 \mathrm{~m})$. There were no clear differences in the levels of these compounds between the samples collected from the high altitude and low altitude, except for the cultivar 'Starkrimson', in which the contents of procyanidin B2 and (-)-epicatechin were higher at the high altitude. The contents of these compounds were much lower in the samples of the cultivar 'Xinshiji' collected from the very high altitude (around $2000 \mathrm{~m}, 27$ and $20 \mu \mathrm{g} / \mathrm{kg}$, respectively) than the levels in those from the low altitude (500-700 m, 103 and $49 \mu \mathrm{g} / \mathrm{kg}$, respectively). However, it must be pointed out that the sampling location of very high altitude also has much lower latitude compared to the other sampling sites, which might have influenced the contents of these compounds due to the light conditions associated with low latitudes. For example, a previous research has shown a positive correlation between the content of proanthocyanidin dimers and latitude, and a negative correlation between the level of proanthocyanidin dimers and the altitudes of growth locations in the berries of sea buckthorn (Hippophaë rhamnodes L.) [14]. It is possible that both altitude and latitude contributed to the compositional difference within each of the cultivars 'Xinshiji' and 'Qinguan' between the samples collected at different growth sites.

Phlorizin and chlorogenic acid were also the highest in the samples collected from the middle altitudes in most of cultivars $(6-26 \mathrm{~g} / \mathrm{kg}$ and $67-124 \mathrm{~g} / \mathrm{kg}$, respectively). 


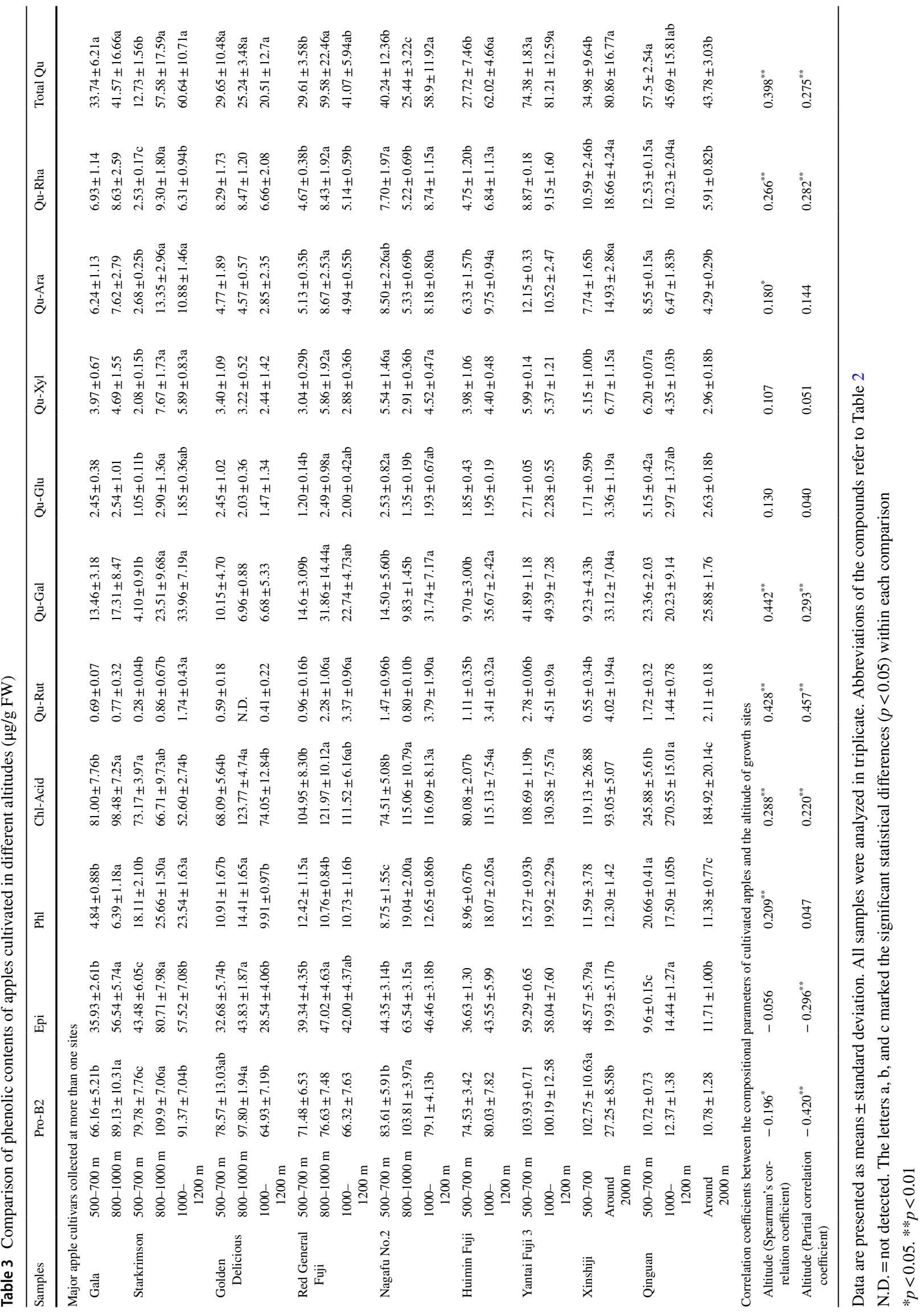


For early and medium ripening cultivars, the contents of chlorogenic acid were similar between the samples from high (1000-1200 m) and low (500-700 m) altitudes, while for all the late-ripening cultivars, namely the 'Qinguan' and 'Fuji' series including 'Nagafu 2', 'Yantai Fuji 3', and 'Huimin Fuji', the content of chlorogenic acid was clearly higher at high altitudes than at low altitudes. The lateripening cultivars usually matured in October-November in Shanxi province, and the decrease in temperature during fruit development and ripening likely have contributed to the impact of altitude on the accumulation of these two compounds in apple fruits. The average content of chlorogenic acid in the 'Qinguan' samples collected from the very high altitude ( $2000 \mathrm{~m}, 185 \mathrm{~g} / \mathrm{kg}$ fresh weight) was significantly lower than those from the high (1000-1200 m, $271 \mu \mathrm{g} / \mathrm{kg}$ ) and low altitude (500-700 m, $246 \mu \mathrm{g} / \mathrm{kg}$ ). Previous research has shown an association between the content of phenolic acids and latitude of growth sites in berries. For example, the study by Yang et al. [39] reported that the contents of hydroxycinnamic acid conjugates in currant (Ribes sp.) cultivars decreased with the decreasing latitude. The lower content of phenolic acid in the cultivar 'Qinguan' could be explained by the low latitude at the growth site at the very high altitude in Yunan province $\left(25^{\circ} 08^{\prime} \mathrm{N}\right.$ compared to $36^{\circ} 07^{\prime} \mathrm{N}$ at high altitude and $34^{\circ}$ $43^{\prime} \mathrm{N}$ at low altitude).

The contents of quercetin glycosides in most cultivars showed a positive association with altitude. Especially in 'Xinshiji', the total content of flavonol glycosides in the samples from the very high altitude was over two folds of the level found in the samples from the low altitude. Ma et al. [40] reported that most of the flavonol glycosides in Chinese sea buckthorn (Hippophaë rhamnoides ssp. sinensis) berries increased as the altitude increased and as the latitude decreased, which was consistent with the results of our findings on apples. However, in the apples of 'Golden Delicious' and 'Qinguan', negative correlations were found between altitude and the content of most quercetin glycosides as well as the total content of quercetin glycosides, suggesting the importance of complex interaction between genetic background and environmental factors.

PCA models were constructed for individual cultivars (Fig. 3). For most cultivars, procyanidin B2, (-)-epicatechin, phlorizin and chlorogenic acid were always the highest in the samples from middle altitude, while the contents of most of the individual quercetin glycosides and the total contents of quercetin glycosides all showed the positive correlations with altitude. However, for the cultivars 'Golden Delicious' and 'Qinguan', the contents of total quercetin glycosides and most individual quercetin glycosides were higher at lower altitudes, again indicating that the responses of phenolic compounds to altitudes variation were influenced by the genetic backgrounds.
Bivariate correlation analysis was also applied to investigate the association of altitude with phenolic compounds in the cultivated apple samples, and partial correlation analysis was further used to investigate the effects of the altitude on the phenolic composition of the apples to exclude the influence from the genotypic difference (Table 3). The partial correlation analysis indicated that the contents of procyanidin B2 and (-)-epicatechin had a negative correlation with altitude $(p<0.01)$. In contrast, the contents of other phenolic compounds were all correlated positively with altitude, of which the correlation between altitude and the contents of quercetin-3-O-rutinoside, quercetin-3-O-galactoside, quercetin-3-O-rhamnoside, total quercetin glycosides and chlorogenic acid was statistically significant in both analy$\operatorname{ses}(p<0.01)$.

Despite the large number of research published on phenolic compounds of apples, little information exists on the impact of altitudes or latitudes on the accumulation of these compounds in apple fruits. Phenolic compounds were studied in "Delicious" group of apples ('Golden Delicious', 'Red Delicious', and 'Royal Delicious') cultivated at five different locations with varying altitudes (1771-2780 m) in Western Himalaya. The highest contents of total phenolic compounds, total flavonoids and total flavonols were found in the fruits from locations at the highest altitude (Mukhawa, $2780 \mathrm{~m}$ ) than those from locations at lower altitudes [41]. A recently published research showed that variation in altitudeinduced changes in multiple biochemical pathways in apple peels of the cultivar 'Fujiku' during the fruit ripening [42]. Phenolic compounds of all the groups were increased at high altitude $(750 \mathrm{~m})$ compared to low altitude $(20 \mathrm{~m})$ accompanied by elevated expression of some key enzymes involved in the biosynthesis of these compounds. In addition, a clear increase was observed in the accumulation of a number of carbohydrate compounds.

The elevation of altitude will induce complex environmental changes, such as enhanced light radiation, decreased air relative humidity and temperature sum, but increased temperature variation. Some reports indicated that flavonols could absorb shorter wavelengths of light to prevent excessive UV-B radiation, therefore, when UV radiation increases, plants adapt to this change by increasing the accumulation of these compounds $[39,43]$. The research of Hagen et al. [44] also indicated that the accumulation of anthocyanins, quercetin glycosides, and chlorogenic acid in apple increased upon postharvest irradiation. Some studies have shown that low temperature induces the synthesis and accumulation of anthocyanins, hydroxycinnamic acid, flavonoid glycosides and total phenolic contents in apples and/or some other fruits and vegetables [19, 21, 39, 45], while the accumulation of proanthocyanidins in grapes is reduced at low temperatures as reported by Cohen et al. [46]. The study of Zhang et al. [18] focused on the effects of environmental humidity on the 

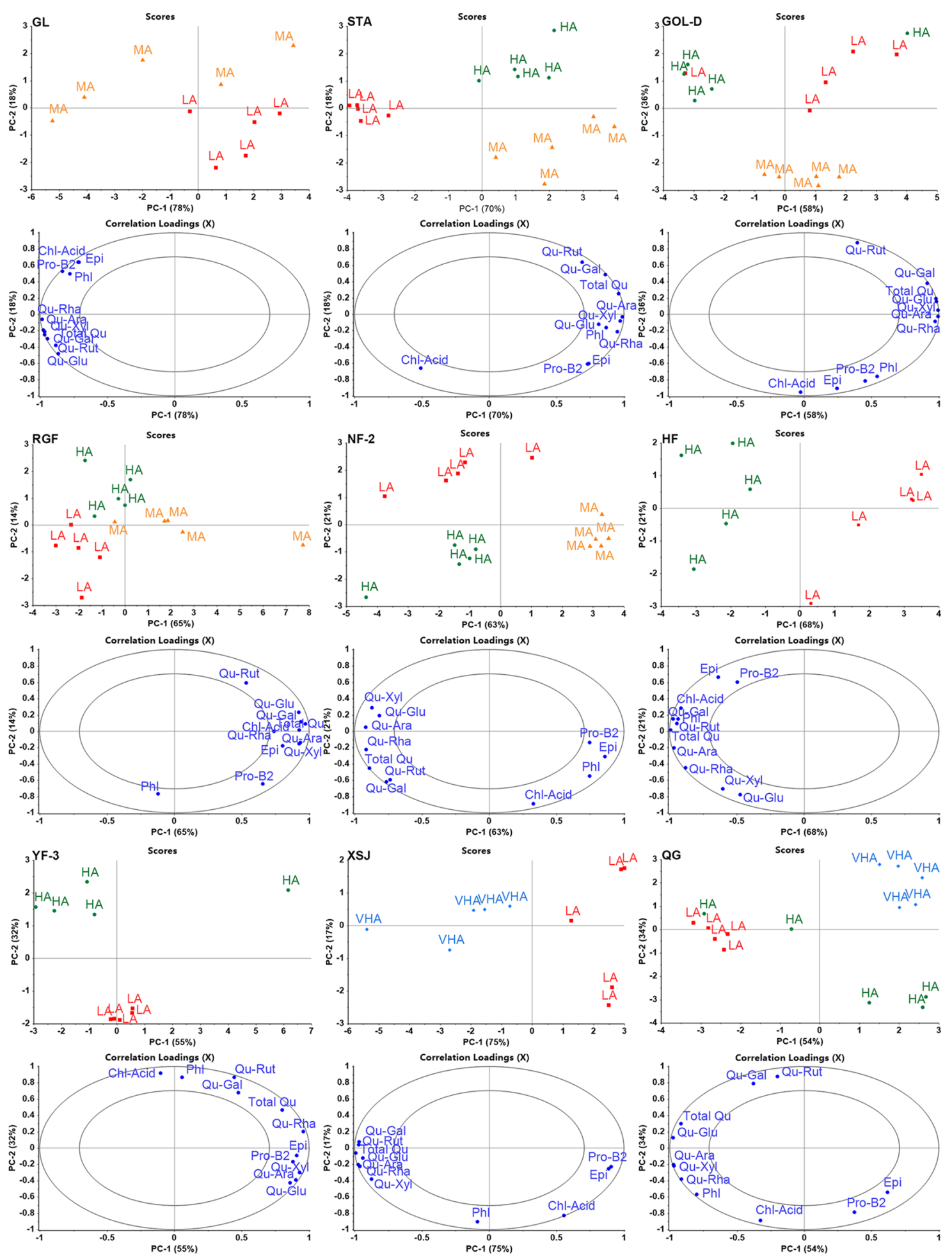

Fig. 3 Scores and loadings plots of PCA model with the first and second factors for nine cultivars collected at two or three grow site with different altitudes (LA, low altitude; MA, medium-altitude; HA, high altitude; and VHA, very high altitude) were classified according to phenolic compound contents ( $n=10$ or 15$)$. Abbreviations of the cultivars refer to Table 1 and abbreviations of the compounds refer to Table 2 
phenolic composition of apples suggesting that high humidity during fruit development and ripening is beneficial to the accumulation of phenolic compounds in the fruits of 'Fuji' apple. Research of Yang et al. [39] indicated that low temperature, low humidity, as well as low radiation are beneficial to the synthesis of hydroxycinnamic acid in currants (Ribes sp.), but their experimental fields located quite far north with the latitude of $60^{\circ}-70^{\circ} \mathrm{N}$, with extreme light conditions. It could be concluded that the decline in chlorogenic acid contents in the samples from the high altitude and the very high altitude in our study may have been due to the combined effects of different environmental factors at the growth sites. The influences of various environmental factors on the phenolic composition are complex, and the results of the interaction of multiple factors may be different from the changes caused by the action of a single-factor. For example, the study conducted by Bakhshi et al. [22] showed that the effect of UV-B irradiation on phenolic compound accumulation in 'Jonathan' apple was influenced by bagging, temperature and maturation. And Arakawa [47] proposed that the optimal temperatures for anthocyanin accumulation were different for bagged fruits compared with those for non-bagged fruits of some apple cultivars including 'Jonathan', 'Fuji', and'Jonagold', due to the impact of bagging treatment on light radiation and temperature on the surface of the fruits.

\section{Effect of bagging on phenolic compounds composition}

The impact of bagging treatment was studied in 'Starkrimson' at the low and high altitude and 'Qinguan' at a high altitude. As shown in Fig. 4, bagging treatment decreased the levels of most phenolic compounds, especially in 'Starkrimson'. However, there were some exceptions: the content of chlorogenic acid in the bagged samples with a 5-day reexposure before harvest was similar to that of the unbagged fruits, and the content of quercetin-3-O-rutinoside in bagged apples with 10 days of re-exposure was higher than the level in the corresponding unbagged fruits. In previous studies, no significant difference was found in the contents of chlorogenic acid in the peel or flesh between the unbagged and the bagged fruits of 'Red Delicious' [48, 49]. Quercetin glycosides are more concentrated in the peel than in the flesh, thus are more sensitive to the bagging treatment [50]. A previous study also indicated that the content of quercetin-3-O-rutinoside in the fruit peel of 'Red Delicious' was greatly reduced by fruit bagging, but re-exposure for 9 days after the bag removal could increase its content to a level similar to that in the unbagged fruits [49]. Unlike the situation for 'Starkrimson', the bagging treatment significantly lowered the contents of only chlorogenic acid and quercetin-3-O-rhamnoside of 'Qinguan' apples, while the levels of procyanidin B2 and phloridzin in the bagged apples exceeded significantly those in the unbagged fruits. No statistically significant difference was found in the contents of the other six phenolic compounds between the fruits of 'Qinguan' with and without bagging treatment. The syntheses of most of the phenolic compounds are notably inhibited in the bagged apple fruits. However, longer-term bagging may result in a higher sensitivity of fruits to sunlight irradiation, and the synthesis may be induced dramatically by re-exposure to light after removal of the bags [49]. Therefore the contents of phenolic compounds in the fruits will likely increase after removal of the bags as the period of re-exposure is extended. In some cases, the levels of some phenolic compounds in the fruits treated with bagging followed by a long period of re-exposure may even exceed those in unbagged fruits. To summarize, the phenolic compounds in the apple fruits showed cultivar-specific responses to fruit bagging treatment, and the content of phenolic compounds was also affected by the number of days of re-exposure to the sunlight before harvest. Previous research has suggested that organic farming may increase the content of phenolic compounds in apple fruits [51]. The findings of the current study and previous research highlight the importance of cultivation practices, together with that of genetic background and environment, as factors influencing the composition and quality of apple fruits.

\section{Conclusion}

The composition and content of phenolic compounds affects the sensory quality, nutritional value, and health-promoting properties of apples and apple products. Currently, there is a lack of knowledge on the impact of altitude of orchards on the accumulation of phenolic compounds in apple fruits. Even less is known about the difference among cultivars in their response to the growth environment. In this study, we investigated the phenolic compounds in seventeen commercial apple cultivars as well as three forms of wild apples grown at different altitudes in Shanxi Province (China) as a globally major apple production region. Our study revealed the impact of genetic background, the altitude of the growth sites, and bagging treatment on the content and profile of phenolic compounds in apple fruits. Among the seventeen commercial cultivars, 'Qinguan' and 'Liuyuehong' were clearly separated from other cultivars such as cultivar series of 'Fuji', 'Gala' and 'Red Delicious' by the special composition of phenolic compounds. The cultivar 'Qinguan' had the highest level of chlorogenic acid but the lowest content of flavan-3-ols, while 'Liuyuehong' had the highest content of flavonoids. The three forms of wild apples in this study were characterized with high phenolic contents and could be used for breeding of specific new varieties suitable for processing. The contents of procyanidin B2 and (-)-epicatechin 

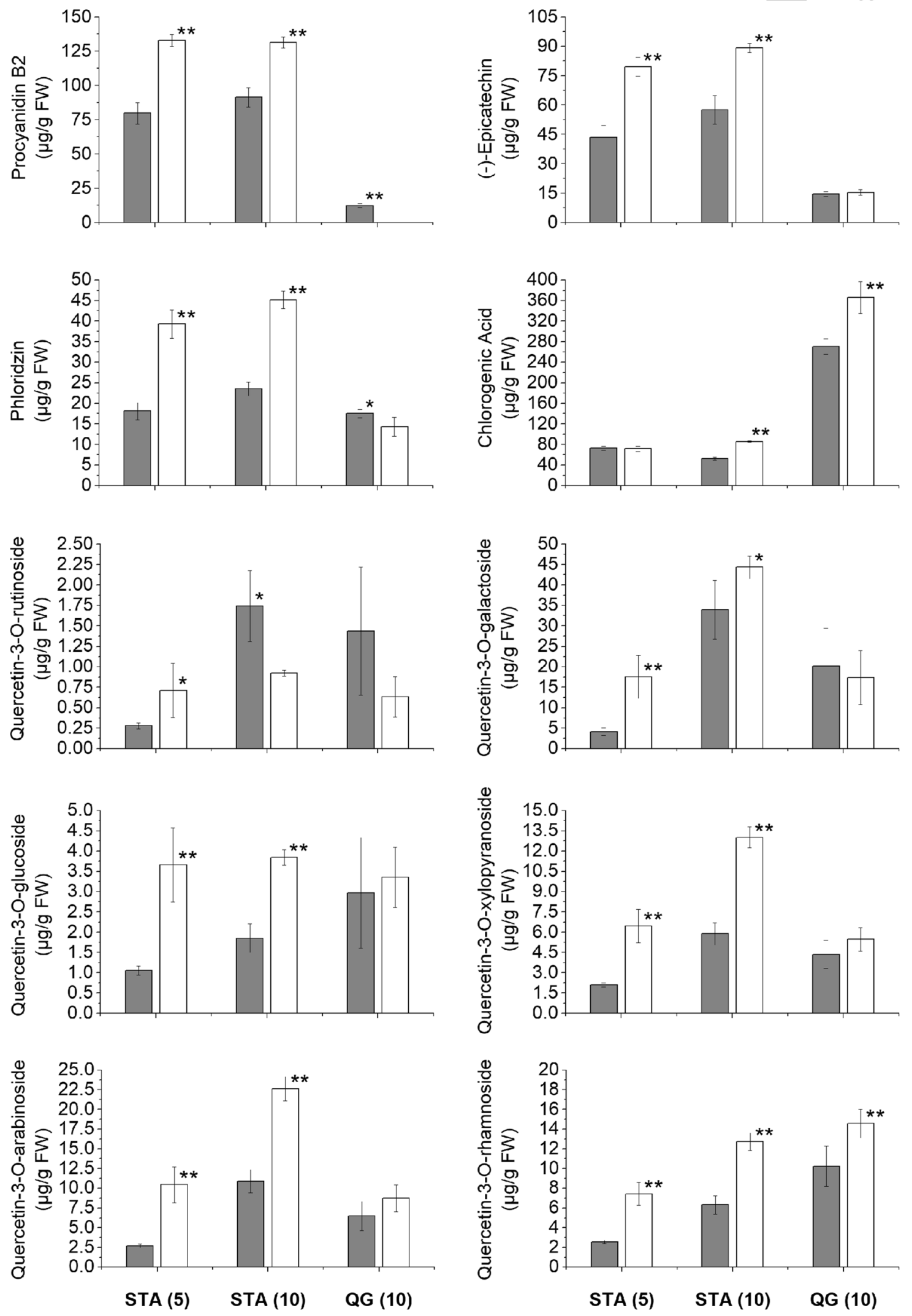
४Fig. 4 Response of phenolic compounds concentrations in 'Starkrimson' (STA) and 'Qinguan' (QG) apples to fruit bagging treatment. Each bar is mean \pm standard deviation $(n=5)$. the Symbol $(*)$ indicates a significant difference between unbagged and bagged fruits at $p<0.05$, and Symbol (**) indicates a significant difference between unbagged and bagged fruits at $p<0.01$. Number in the brackets after culitivar abbreviation means the days of re-exposure after bag removal of bagged samples. Bagged and Unbagged samples of STA (5) were collected from Yuncheng, those of STA (10) and QG (10) from Linfen

showed a negative correlation with altitude, while other phenolic compounds were all correlated positively with altitude. Bagging treatment reduced the contents of most phenolic compounds in apples, but the impact was strongly dependent on the genetic background of the cultivars and the length of the re-exposure time after bagging treatment. Our study adds important knowledge on the composition and quality of apple produce and apple resources. This research is the first systematic study on phenolic compounds of many major cultivars cultivated in China, a globally major country of apple production. This is also the first report on the impact of altitude of growth locations on the accumulation of phenolic compounds in nine major commercial apple cultivars. Our findings provide important guidance for cultivation and plant breeding as well as commercial processing and high value-added utilization of apples.

Supplementary Information The online version contains supplementary material available at https://doi.org/10.1007/s00217-021-03695-0.

Acknowledgements The authors would like to thank Dr. Wei Yang (University of Turku) for his support in the analysis work.

Author contributions Conceptualization: BY, XQ, SQ; methodology: BY, YL, ZN; formal analysis and investigation: YL, BY, HS, JL, ZN; writing —original draft preparation: YL; writing — review and editing: BY, YL, SQ, XQ, JL, ZN; funding acquisition: BY, SQ; resources: SQ, BY, XQ; supervision: BY, JL, SQ, XQ.

Funding The research was funded by Shanxi Academy of Agricultural Sciences (currently, Shanxi Agricultural University), China (Grant Decision in 2018) in the project "Metabolomics research and biotechnology for processing and value addition of apples". Open Access funding was provided by University of Turku (UTU) including Turku University Central Hopsital.

\section{Compliance with ethical standards}

Conflict of interest The authors declare that they have no conflict of interest.

Ethical approval This research does not include any studies with human subjects or animal experiments.

Open Access This article is licensed under a Creative Commons Attribution 4.0 International License, which permits use, sharing, adaptation, distribution and reproduction in any medium or format, as long as you give appropriate credit to the original author(s) and the source, provide a link to the Creative Commons licence, and indicate if changes were made. The images or other third party material in this article are included in the article's Creative Commons licence, unless indicated otherwise in a credit line to the material. If material is not included in the article's Creative Commons licence and your intended use is not permitted by statutory regulation or exceeds the permitted use, you will need to obtain permission directly from the copyright holder. To view a copy of this licence, visit http://creativecommons.org/licenses/by/4.0/.

\section{References}

1. Mihailović NR, Mihailović VB, Kreft S, Ćirić AR, Joksović LG, Đurđević PT (2018) Analysis of phenolics in the peel and pulp of wild apples (Malus sylvestris (L.) Mill.). J Food Compos Anal 67:1-9. https://doi.org/10.1016/j.jfca.2017.11.007

2. Stojiljković D, Arsić I, Tadić V (2016) Extracts of wild apple fruit (Malus sylvestris (L.) Mill., Rosaceae) as a source of antioxidant substances for use in production of nutraceuticals and cosmeceuticals. Ind Crops Prod 80:165-176. https://doi. org/10.1016/j.indcrop.2015.11.023

3. Raudone L, Raudonis R, Liaudanskas M, Janulis V, Viskelis P (2017) Phenolic antioxidant profiles in the whole fruit, flesh and peel of apple cultivars grown in Lithuania. Sci Hortic 216:186192. https://doi.org/10.1016/j.scienta.2017.01.005

4. Hyson DA (2011) A comprehensive review of apples and apple components and their relationship to human health. Adv Nutr 2(5):408-420. https://doi.org/10.3945/an.111.000513

5. Plenol-Explorer 3.6: Database on polyphenol contents in foods. (2015) http://phenol-explorer.eu/

6. Wu S, Yue Y, Li J, Li Z, Li X, Niu Y, Xiang J, Ding H (2015) Procyanidin B2 attenuates neurological deficits and bloodbrain barrier disruption in a rat model of cerebral ischemia. Mol Nutr Food Res 59(10):1930-1941. https://doi.org/10.1002/ mnfr.201500181

7. Bernatova I (2018) Biological activities of (-)-epicatechin and (-)-epicatechin-containing foods: Focus on cardiovascular and neuropsychological health. Biotechnol Adv 36(3):666-681. https://doi.org/10.1016/j.biotechadv.2018.01.009

8. Shilpi A, Parbin S, Sengupta D, Kar S, Deb M, Rath SK, Pradhan N, Rakshit M, Patra SK (2015) Mechanisms of DNA methyltransferase-inhibitor interactions: procyanidin B2 shows new promise for therapeutic intervention of cancer. Chem-Biol Interact 233:122-138. https://doi.org/10.1016/j.cbi.2015.03.022

9. Naveed M, Hejazi V, Abbas M, Kamboh AA, Khan GJ, Shumzaid M, Ahmad F, Babazadeh D, FangFang X, Modarresi-Ghazani F, WenHua L, XiaoHui Z (2018) Chlorogenic acid (CGA): a pharmacological review and call for further research. Biomed Pharmacother 97:67-74. https://doi.org/10.1016/j. biopha.2017.10.064

10. Puel C, Quintin A, Mathey J, Obled C, Davicco MJ, Lebecque P, Kati-Coulibaly S, Horcajada MN, Coxam V (2005) Prevention of bone loss by phloridzin, an apple polyphenol, in ovariectomized rats under inflammation conditions. Calcif Tissue Int 77(5):311-318. https://doi.org/10.1007/s00223-005-0060-5

11. Xiang L, Sun K, Lu J, Weng Y, Taoka A, Sakagami Y, Qi J (2011) Anti-aging effects of phloridzin, an apple polyphenol, on yeast via the SOD and Sir2 genes. Biosci Biotechnol Biochem 75(5):854-858. https://doi.org/10.1271/bbb.100774

12. Graefe E, Wittig J, Mueller S, Riethling A-K, Uehleke B, Drewelow B, Pforte H, Jacobasch G, Derendorf H, Veit M (2001) Pharmacokinetics and bioavailability of quercetin 
glycosides in humans. J Clin Pharmacol 41:492-499. https:// doi.org/10.1177/009127000104100503

13. Hufnagel JC, Hofmann T (2008) Orosensory-directed identification of astringent mouthfeel and bitter-tasting compounds in red wine. J Agric Food Chem 56(4):1376-1386. https://doi. org/10.1021/jf073031n

14. Yang W, Laaksonen O, Kallio H, Yang B (2016) Proanthocyanidins in sea buckthorn (Hippophae rhamnoides L.) berries of different origins with special reference to the influence of genetic background and growth Location. J Agric Food Chem 64(6):1274-1282. https://doi.org/10.1021/acs.jafc.5b05718

15. Symoneaux R, Baron A, Marnet N, Bauduin R, Chollet S (2014) Impact of apple procyanidins on sensory perception in model cider (part 1): Polymerization degree and concentration. LWTFood Sci Technol 57(1):22-27

16. Ibdah M, Martens S, Gang DR (2018) Biosynthetic pathway and metabolic engineering of plant dihydrochalcones. J Agric Food Chem 66(10):2273-2280. https://doi.org/10.1021/acs. jafc.7b04445

17. Aachary AA and Eskin MNA (2017) In: Aliani M and Eskin MNA (eds) Bitterness: perception, chemistry and food processing, John Wiley \& Sons, Incorporated, New York

18. Zhang M, Zhang G, You Y, Yang C, Li P, Ma F (2016) Effects of relative air humidity on the phenolic compounds contents and coloration in the 'Fuji' apple (Malus domestica Borkh.) peel. Sci Hortic 201:18-23. https://doi.org/10.1016/j.scienta.2016.01.017

19. Lin-Wang K, Micheletti D, Palmer J, Volz R, Lozano L, Espley R, Hellens RP, Chagne D, Rowan DD, Troggio M, Iglesias I, Allan AC (2011) High temperature reduces apple fruit colour via modulation of the anthocyanin regulatory complex. Plant Cell Environ 34(7):1176-1190. https://doi.org/10.111 1/j.1365-3040.2011.02316.x

20. Jakopic J, Stampar F, Veberic R (2009) The influence of exposure to light on the phenolic content of 'Fuji' apple. Sci Hortic 123(2):234-239. https://doi.org/10.1016/j.scienta.2009.09.004

21. Pan H-h, Shü Z-h (2007) Temperature affects color and quality characteristics of 'Pink' wax apple fruit discs. Sci Hortic 112(3):290-296. https://doi.org/10.1016/j.scienta.2006.12.046

22. Bakhshi D, Arakawa O (2006) Effects of UV-B irradiation on phenolic compound accumulation and antioxidant activity in "Jonathan" apple influenced by bagging, temperature and maturation. J Food Agric Environ 4:75-79

23. Lee KW, Kim YJ, Kim D-O, Lee HJ, Lee CY (2003) Major phenolics in apple and their contribution to the total antioxidant capacity. J Agric Food Chem 51(22):6516-6520. https://doi. org/10.1021/jf034475w

24. Vrhovsek U, Rigo A, Tonon D, Mattivi F (2004) Quantitation of polyphenols in different apple varieties. J Agric Food Chem 52(21):6532-6538. https://doi.org/10.1021/jf049317z

25. Stanger MC, Steffens CA, Soethe C, Moreira MA, do Amarante CVT (2017) Phenolic content and antioxidant activity during the development of "Brookfield" and "Mishima" apples. J Agric Food Chem 65(17):3453-3459. https://doi.org/10.1021/acs.jafc.6b046 95

26. Lee J, Chan BL, Mitchell AE (2017) Identification/quantification of free and bound phenolic acids in peel and pulp of apples (Malus domestica) using high resolution mass spectrometry (HRMS). Food Chem 215:301-310. https://doi.org/10.1016/j. foodchem.2016.07.166

27. Zupan A, Mikulic-Petkovsek M, Slatnar A, Stampar F, Veberic $\mathrm{R}$ (2014) Individual phenolic response and peroxidase activity in peel of differently sun-exposed apples in the period favorable for sunburn occurrence. J Plant Physiol 171(18):1706-1712. https:// doi.org/10.1016/j.jplph.2014.08.010

28. Liu F, Wang M, Wang M (2018) Phenolic compounds and antioxidant activities of flowers, leaves and fruits of five crabapple cultivars (Malus Mill. species). Sci Hortic 235:460-467. https:// doi.org/10.1016/j.scienta.2018.02.051

29. Zhou K, Hu L, Liu B, Li Y, Gong X, Ma F (2018) Identification of apple fruits rich in health-promoting dihydrochalcones by comparative assessment of cultivated and wild accessions. Sci Hortic 233:38-46. https://doi.org/10.1016/j.scienta.2018.01.042

30. Wu J, Gao H, Zhao L, Liao X, Chen F, Wang Z, Hu X (2007) Chemical compositional characterization of some apple cultivars. Food Chem 103(1):88-93. https://doi.org/10.1016/j.foodc hem.2006.07.030

31. Tian Y, Gou X, Niu P, Sun L, Guo Y (2018) Multivariate data analysis of the physicochemical and phenolic properties of not from concentrate apple juices to explore the alternative cultivars in juice production. Food Anal Method 11(6):1735-1747. https ://doi.org/10.1007/s12161-018-1169-2

32. Arts ICW, van de Putte B, Hollman PCH (2000) Catechin contents of foods commonly consumed in the Netherlands. 1. Fruits, vegetables, staple foods, and processed foods. J Agric Food Chem 48(5):1746-1751. https://doi.org/10.1021/jf000025h

33. Valavanidis A, Vlachogianni T, Psomas A, Zovoili A, Siatis V (2009) Polyphenolic profile and antioxidant activity of five apple cultivars grown under organic and conventional agricultural practices. Int J Food Sci Technol 44(6):1167-1175. https ://doi.org/10.1111/j.1365-2621.2009.01937.x

34. Feliciano RP, Antunes C, Ramos A, Serra AT, Figueira ME, Duarte CMM, Carvalho Ad, Bronze MR (2010) Characterization of traditional and exotic apple varieties from Portugal. Part 1-Nutritional, phytochemical and sensory evaluation. J Funct Foods 2(1):35-45. https://doi.org/10.1016/j.jff.2009.12.004

35. Serra AT, Rocha J, Sepodes B, Matias AA, Feliciano RP, de Carvalho A, Bronze MR, Duarte CM, Figueira ME (2012) Evaluation of cardiovascular protective effect of different apple varieties - correlation of response with composition. Food Chem 135(4):2378-2386. https://doi.org/10.1016/j.foodc hem.2012.07.067

36. Ceymann M, Arrigoni E, Schärer H, Baumgartner D, Nising AB, Hurrell RF (2011) Rapid high performance screening method using UHPLC-MS to quantify 12 polyphenol compounds in fresh apples. Anal Methods 3(8):1774-1778. https:// doi.org/10.1039/c1ay05152k

37. Ceymann M, Arrigoni E, Schärer H, Bozzi Nising A, Hurrell RF (2012) Identification of apples rich in health-promoting flavan3 -ols and phenolic acids by measuring the polyphenol profile. J Food Compos Anal 26(1-2):128-135. https://doi.org/10.1016/j. jfca.2011.12.002

38. Han M, Wang C, Hu H, Wu Y, Zhang L (2018) Analysis of compostion and content of polyphenols in Qingyang red fuji apple (In Chinese). Sci Technol Food Ind 39(20):244-248. https ://doi.org/10.13386/j.issn1002-0306.2018.20.041

39. Yang B, Zheng J, Laaksonen O, Tahvonen R, Kallio H (2013) Effects of latitude and weather conditions on phenolic compounds in currant (Ribes spp.) cultivars. J Agric Food Chem 61(14):3517-3532. https://doi.org/10.1021/jf4000456

40. Ma X, Laaksonen O, Zheng J, Yang W, Trepanier M, Kallio H, Yang B (2016) Flavonol glycosides in berries of two major subspecies of sea buckthorn (Hippophae rhamnoides L.) and influence of growth sites. Food Chem 200:189-198. https://doi. org/10.1016/j.foodchem.2016.01.036

41. Dhyani P, Bahukhandi A, Rawat S, Bhatt ID, Rawal RS (2018) Diversity of bioactive compounds and antioxidant activity in Delicious group of apple in Western Himalaya. J Food Sci Technol 55(7):2587-2599. https://doi.org/10.1007/s1319 7-018-3179-x

42. Karagiannis E, Michailidis M, Tanou G, Scossa F, Sarrou E, Stamatakis G, Samiotaki M, Martens S, Fernie AR, Molassiotis A (2020) Decoding altitude-activated regulatory mechanisms 
occurring during apple peel ripening. Hortic Res 7:120. https:// doi.org/10.1038/s41438-020-00340-x

43. Treutter D (2006) Significance of flavonoids in plant resistance: a review. Environ Chem Lett 4(3):147-157. https://doi.org/10.1007/ s10311-006-0068-8

44. Hagen SF, Borge GIA, Bengtsson GB, Bilger W, Berge A, Haffner K, Solhaug KA (2007) Phenolic contents and other health and sensory related properties of apple fruit (Malus domestica Borkh., cv. Aroma): effect of postharvest UV-B irradiation. Postharvest Biol Technol 45(1):1-10. https://doi.org/10.1016/j.posth arvbio.2007.02.002

45. Neugart S, Krumbein A, Zrenner R (2016) Influence of light and temperature on gene expression leading to accumulation of specific flavonol glycosides and hydroxycinnamic acid derivatives in kale (Brassica oleracea var. sabellica). Front Plant Sci 7(222):326. https://doi.org/10.3389/fpls.2016.00326

46. Cohen SD, Tarara JM, Gambetta GA, Matthews MA, Kennedy JA (2012) Impact of diurnal temperature variation on grape berry development, proanthocyanidin accumulation, and the expression of flavonoid pathway genes. J Exp Bot 63(7):2655-2665. https:// doi.org/10.1093/jxb/err449

47. Arakawa O (1991) Effect of temperature on anthocyanin accumulation in apple fruit as affected by cultivar, stage of fruit ripening and bagging. J Hortic Sci 66(6):763-768. https://doi. org/10.1080/00221589.1991.11516209
48. Chen C-S, Zhang D, Wang Y-Q, Li P-M, Ma F-W (2012) Effects of fruit bagging on the contents of phenolic compounds in the peel and flesh of 'Golden Delicious', 'Red Delicious', and 'Royal Gala' apples. Sci Hortic 142:68-73. https://doi.org/10.1016/j. scienta.2012.05.001

49. Sun S, Xin L, Gao H, Wang J, Li P (2014) Response of phenolic compounds in 'Golden Delicious' and 'Red Delicious' apples peel to fruit bagging and subsequent sunlight re-exposure. Sci Hortic 168:161-167. https://doi.org/10.1016/j.scienta.2014.01.031

50. Feng F, Li M, Ma F, Cheng L (2014) The effects of bagging and debagging on external fruit quality, metabolites, and the expression of anthocyanin biosynthetic genes in 'Jonagold' apple (Malus domestica Borkh.). Sci Hortic 165:123-131. https://doi. org/10.1016/j.scienta.2013.11.008

51. Średnicka-Tober D, Barański M, Kazimierczak R, Ponder A, Kopczyńska K, Hallmann E (2020) Selected antioxidants in organic vs. conventionally grown apple fruits. Appl Sci 10(9):2997

Publisher's Note Springer Nature remains neutral with regard to jurisdictional claims in published maps and institutional affiliations. 